Bài báo khoa học

\title{
Đánh giá chất lượng nước theo mùa và xác định nguyên nhân thay đổi màu nước hồ nước xanh xã An Sơn, huyện Thủy Nguyên, thành phố Hải Phòng
}

Đỗ Hữu Tuấn ${ }^{1}$

\author{
${ }^{1}$ Khoa môi trường, Trường Đại học Khoa học Tự nhiên, Đại học Quốc gia Hà Nội; \\ tuandh@vnu.edu.vn \\ *Tác giả liên hệ: tuandh@vnu.edu.vn; Tel: +84-2438584995
}

Ban Biên tập nhận bài:12/5/2021 Ngày phản biện xong: 27/7/2021 Ngày đăng bài: $25 / 10 / 2021$

Tóm tắt: Màu nước của hồ nước xanh tại An Sơn, huyện Thủy Nguyên, thành phố Hải Phòng thay đổi rõ rệt giữa hai mùa mùa mưa và mùa khô. Việc đánh giá chất lượng nước của hồ theo mùa và nguyên nhân của sự thay đổi màu của nước giữa hai mùa là hết sức cần thiết. Qua khảo sát thực địa lấy mẫu phân tích các thành phần hóa học trong nước, đánh giá chất lượng nước kết quả cho thấy chất lượng nước rất kém $(\mathrm{WQI}=1)$. Tổng chất rắn lơ lửng TSS tăng từ $0,05 \mathrm{mg} / 1$ mùa khô lên $7,83 \mathrm{mg} / 1$ mùa mưa và độ đục tăng từ $1,0 \mathrm{NTU}$ mùa khô lên $2,2 \mathrm{NTU}$ mùa mưa. Trong khi đó nồng độ $\mathrm{CaCO}_{3}$ và $\mathrm{Ca}\left(\mathrm{HCO}_{3}\right)_{2}$ đều giảm vào mùa mưa $\left(\mathrm{CaCO}_{3}\right.$ giảm từ $304 \mathrm{mg} / 1$ mùa khô xuống $240 \mathrm{mg} / 1$ mùa mưa, $\mathrm{Ca}\left(\mathrm{HCO}_{3}\right)_{2}$ giảm từ 67,75 $\mathrm{mg} / \mathrm{l}$ xuống 47,21 mg/l). Độ sâu Sechi giảm từ 17,5 m (mùa khô) xuống 6,5 m (mùa mưa). Chất rắn lơ lửng và độ đục tăng, nồng độ $\mathrm{CaCO}_{3}$ và $\mathrm{Ca}\left(\mathrm{HCO}_{3}\right)_{2}$ giảm vào mùa mưa được xác định là nguyên nhân dẫn tới màu nước mùa hè có màu xanh lam nhạt hơn mùa khô.

Từ khóa: Chất lượng nước hồ; Hồ nước xanh; Màu nước hồ thay đổi.

\section{Mở đầu}

Hồ nước xanh là hồ nước nhân tạo nằm trong khu vực mỏ đá Trại Sơn, xã An Sơn huyện Thủy Nguyên thành phố Hải Phòng. Hồ hình thành do hoạt động khai thác đá vôi trong khu vực. Phía bắc của hồ là khu vực khai thác đá vôi của công ty xi măng Phúc Sơn, phía nam và phía tây giáp với khu vực sản xuất nông nghiệp của xã An Sơn, chủ yếu là canh tác lúa nước. Ở phía đông của hồ, có các hoạt động nung vôi, lấy nguyên liệu từ khu vực khai thác đá. Hồ có màu xanh lam đặc trưng đã thu hút nhiều khác du lịch đến khám phá. Tuy nhiên màu nước của hồ thay đổi theo mùa trong đó mùa mưa xanh nhạt, mùa khô xanh đậm. Các nghiên cứu quốc tế đã chỉ ra rằng chất lượng nước hồ có thể thay đổi theo mùa và ảnh hưởng tới sức khỏe người dân bởi những đặc tính nguồn ô nhiễm theo mùa [1-2]. Khi chất lượng nước hồ thay đồi theo mùa thì màu sắc của nước hồ cũng bị thay đổi đi kèm với sự biến đổi về tính chất hóa lý như hồ Tiwi Ata Mbupu ở Indonesia, hay hồ nước xanh (The blue lake) ở Nam Austrialia.

Đánh giá chất lượng nước hồ là một trong những nội dung quan trọng trong việc quản lý khai thác sử dụng bền vững nước hồ [3-5] đặc biệt là sự biến đồi chất lượng nước theo mùa [6]. Để đánh giá chất lượng nước hồ cũng như các thông số gây ô nhiễm hiện nay có thể sử dụng các phương pháp như WQI [7-9], thống kê [10-12]. Chỉ số WQI đã được áp dụng rộng 
rãi tại các nước như Ấn Độ [13], Trung Quốc [14] Mỹ, Canada [15] để đánh giá tổng quát nhất về chất lượng nước mặt. Tại Việt Nam Bộ Tài Nguyên và Môi trường đã ban hành phương pháp tính chỉ số chất lượng nước WQI qua các thông số chất lượng nước [16]. Các nghiên cứu trong nước cũng đã áp dụng phương pháp tính chỉ số WQI để đánh giá chất lượng nước mặt [17-19]. Ngoài phương pháp sử dụng WQI để đánh giá chất lượng nước tổng hợp, phương pháp so sánh từng chỉ tiêu đơn lẻ với Quy chuẩn để xác định các chỉ tiêu vượt ngưỡng cho phép cũng được áp dụng rộng rãi. U’u điểm của phương pháp so sánh chỉ tiêu đơn lẻ là mức độ chi tiết tới từng chỉ tiêu, dễ dàng xác định mức độ ô nhiễm của từng chỉ tiêu đó. Trong nghiên cứu này, cả hai phương pháp là phương pháp chỉ số WQI và so sánh chỉ tiêu đơn lẻ với Quy chuẩn đã được áp dụng để vừa có đánh giá tổng quan vừa chi tiết về các chỉ tiêu chất lượng nước hồ.

Từ yêu cầu thực tế về quản lý chất lượng nước phục vụ cho việc định hướng khai thác và sử dụng nước hồ, 2 mục tiêu của nghiên cứu là: (1) Đánh giá chất lượng nước hồ theo mùa; (2) Bước đầu xác định nguyên nhân màu nước hồ thay đổi theo mùa.

\section{Phương pháp nghiên cứu}

Đối tượng nghiên cứu: là chất lượng nước hồ bao gồm các thông số: $\mathrm{pH}, \mathrm{TSS}, \mathrm{BOD}$, $\mathrm{COD}, \mathrm{NH}^{4+}, \mathrm{PO}_{4}{ }^{3-}, \mathrm{As}, \mathrm{Cd}, \mathrm{Pb}, \mathrm{Cr}^{6+}, \mathrm{Cu}, \mathrm{Zn}, \mathrm{Ni}, \mathrm{Mn}, \mathrm{Fe}, \mathrm{Hg}$.

Phạm vi nghiên cứu: hồ nước xanh tại khu khai thác đá thuộc xã An Sơn, huyện Thủy Nguyên, thành phố Hải Phòng (Hình 1).

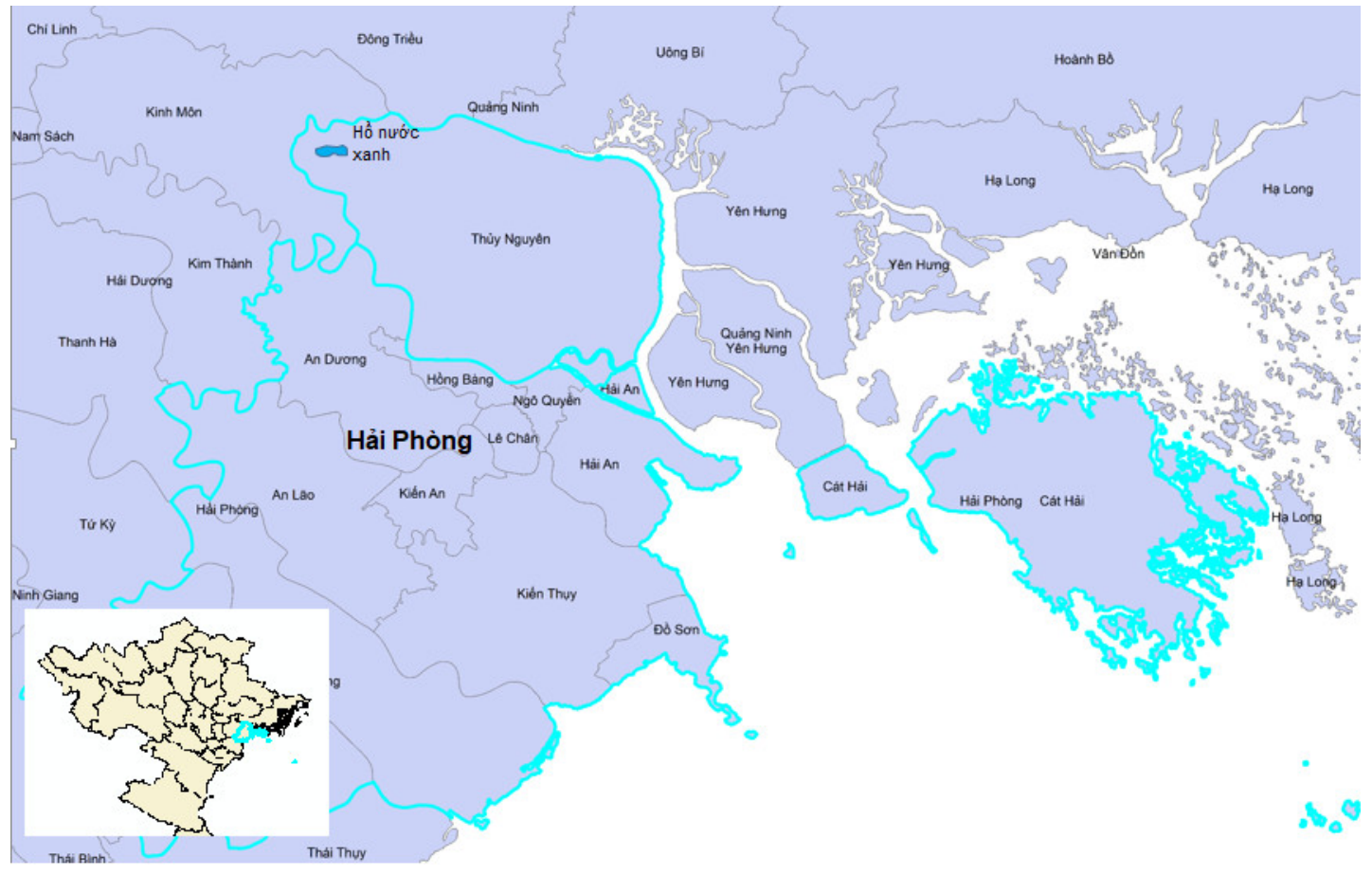

Hình 1. Vị trí khu vực nghiên cứu.

\subsection{Phuoong pháp nghiên cứu}

\subsubsection{Phương pháp lấy mẫu và phân tích mẫu}

Các mẫu nước được lấy tầng mặt vào 2 mùa chính trong năm là mùa mưa (tháng 8 ) và mùa khô (đầu tháng 4) theo Tiêu chuẩn Việt Nam (TCVN): TCVN 5994:1995, TCVN 66631:2011, bảo quản theo TCVN 6663-3:2003 và được phân tích theo Quy chuẩn Việt Nam (QCVN): QCVN 08-MT:2015. Các chỉ tiêu được so sánh với QCVN 08-MT:2015 cột B1. 


\subsubsection{Phương pháp xử lý thống kê}

Các số liệu quan trắc được phân tích xử lý bằng phần mềm lập trình thống kê $\mathrm{R}$ để xác loại bỏ các sai số hệ thống trong quá trình quan trắc.

\subsubsection{Phương pháp chỉ số WQI}

Để tính chỉ số chất lượng nước WQI, nghiên cứu đã áp dụng phương pháp tính WQI của Bộ Tài Nguyên và Môi trường đối với các thông số $\mathrm{BOD}_{5}, \mathrm{COD}, \mathrm{N}-\mathrm{NH}_{4}, \mathrm{P}_{-} \mathrm{PO}_{4}, \mathrm{TSS}$, độ đục, tổng Coliform, DO, pH.

\section{Kết quả nghiên cứu và thảo luận}

\subsection{Chất lương nước hồ theo mùa mura và mùa khô}

Kết quả nghiên cứu cho thấy, chất lượng nước đối với các thông số TSS, $\mathrm{BOD}, \mathrm{NH}_{4}{ }^{+}$, $\mathrm{PO}_{4}{ }^{3-}, \mathrm{COD}$ và các kim loại nặng của cả hai mùa mưa và mùa khô đều thấp hơn $\mathrm{QCVN} 08-$ $\mathrm{MT}$ :2015 cột $\mathrm{B} 1$ (Hình 2). Tuy nhiên, giá trị $\mathrm{pH}$ rất cao lần lượt là 10,02 và 10,21 vào mùa mưa và mùa khô, $\mathrm{pH}$ đều vượt quá QCVN 08-MT:2015 (B1 pH 5,5 - 9). Giá trị pH cao của cả hai mùa cho thấy chất lượng nước của hồ rất kém [20], chỉ số WQI cả 2 mùa đều bằng 1 thể hiện nước bị ô nhiễm nặng, không an toàn khi sử dụng với mục đích B1. Mặc dù nồng độ Ôxy hòa tan DO của cả hai mùa (mùa mưa $4,48 \mathrm{mg} / 1$ và mùa khô $4,7 \mathrm{mg} / \mathrm{l}$ ) đều cao hơn QCVN 08-MT:2015 nhưng do $\mathrm{pH}$ quá cao cùng với nồng độ dinh dưỡng rất thấp $\left(\mathrm{NH}_{4}{ }^{+}<\right.$ $0,02 \mathrm{mg} / 1$ và $\left.\mathrm{PO}_{4}{ }^{3-}<0,05 \mathrm{mg} / \mathrm{l}\right)$ dẫn tới thực vật và động vật trong hồ không phát triển. Kết quả phân tích cho thấy nồng độ coliform bằng 0 , nồng độ diệp lục Clorophin a rất thấp (< $0,002 \mathrm{mg} / \mathrm{l})$. Các thông số As và kim loại nặng như $\mathrm{Cd}, \mathrm{Pb}, \mathrm{Cr}^{6+}, \mathrm{Cu}, \mathrm{Zn}, \mathrm{Ni}, \mathrm{Hg}$ cả hai mùa mưa và mùa khô đều có nồng độ rất thấp nằm dưới ngưỡng quy định của QCVN 08-MT:2015 (B1) (Hình 3). Do đó, hồ nước không bị ô nhiễm kim loại nặng. Khảo sát thực địa cũng cho thấy, hồ không nằm trong vùng có nguy cơ ô nhiễm kim loại nặng do xung quanh hồ chỉ có các hoạt động khai thác đá vôi, nung vôi, nông nghiệp và sinh hoạt.

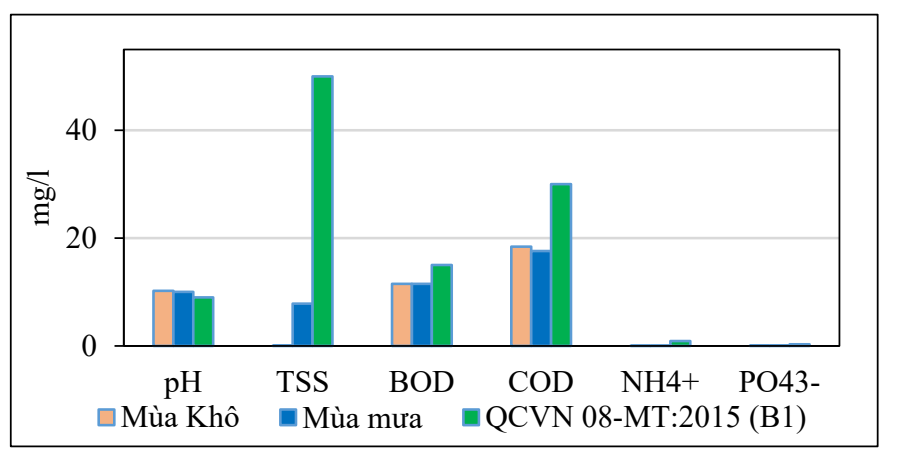

Hình 2. Các giá trị pH, TSS, $\mathrm{BOD}_{5}, \mathrm{COD}, \mathrm{NH}_{4}{ }^{+}, \mathrm{PO}_{4}{ }^{3-}$ vào mùa mưa và mùa khô.

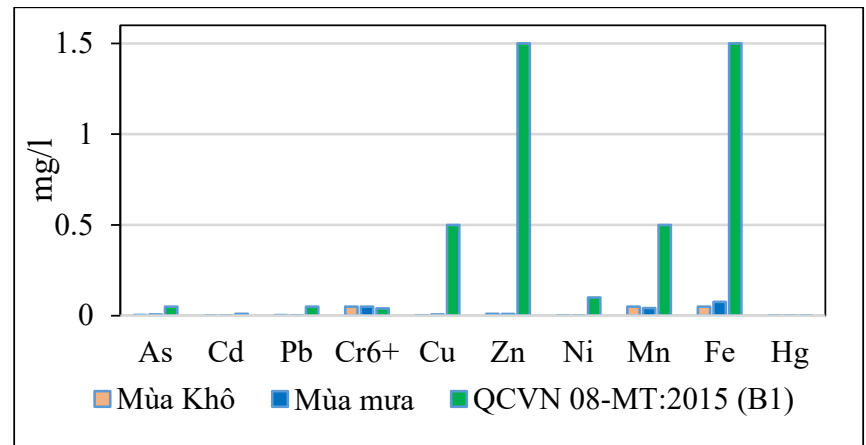

Hình 3. Nồng độ kim loại nặng vào mùa mưa và mùa khô. 


\subsection{Bước đầu xác định nguyên nhân màu nước thay đổi theo mùa mưa và mùa khô}

Kết quả nghiên cứu khảo sát thực địa cho thấy, nước hồ mùa mưa có màu xanh lam nhạt hơn nước hồ vào mùa khô.

\subsubsection{Hiện tượng nước xanh đậm vào mùa khô}

Hồ nước nằm trong khu vực khai thác đá vôi, nước ngầm và nước mặt chảy qua khu khai thác đá, nồng độ $\mathrm{CaCO}_{3}$ cao khi kết tủa đã kéo các hợp chất hữu cơ xuống đáy hồ làm cho chất dinh dưỡng trong hồ rất thấp Amoni $\left(\mathrm{NH}_{4}{ }^{+}\right)$nồng độ $<0,02 \mathrm{mg} / 1$, Photphat $\left(\mathrm{PO}_{4}{ }^{3-}\right)$ nồng độ $<0,05 \mathrm{mg} / \mathrm{l}$ cùng với $\mathrm{pH}$ cao đã làm cho tảo khó phát triển (nồng độ Clorophin $\mathrm{a}<0,002$ $\mathrm{mg} / \mathrm{l})$. Kết quả phân tích cho thấy, $\mathrm{pH}$ mùa khô rất cao $(10,21)$, nồng độ chất rắt lơ lửng rất thấp $(<0,05 \mathrm{mg} / \mathrm{l})$, nước hồ rất trong có thể nhìn thấy đáy vùng ven bờ. Độ sâu Secchi 17,5 m. Các nghiên cứu đã chỉ ra rằng khả năng hấp thụ các bước sóng của ánh sáng trắng từ mặt trời chiếu xuống nước là khác nhau. Nước có khả năng hấp thụ bước sóng kém nhất tại 418 $\mathrm{nm}$ và tăng dần đến bước sóng $700 \mathrm{~nm}$ [21]. Tương ứng đối với các màu cơ bản nước hấp thụ màu đỏ (red) tốt nhất, đến màu vàng (yellow), xanh lá cây (green) và hấp thụ màu xanh lam (blue) là kém nhất. Do đó đối với hồ nước trong và sâu màu xanh lam sẽ bị tán xạ mạnh nhất và ta nhìn thấy hồ nước có màu xanh lam.

Bên cạnh đó, màu của nước còn ảnh hưởng bởi các chất hòa tan, chất lơ lửng trong nước. Kết quả nghiên cứu cho thấy, mùa khô nồng độ $\mathrm{CaCO}_{3}$ rất cao $(304 \mathrm{mg} / \mathrm{l})$. Trong khi các hợp chất hữu cơ hòa tan, chất lơ lửng tán xạ ánh sáng trong khoảng từ vàng đến nâu thì $\mathrm{CaCO}_{3}$ tán xạ mạnh ánh sáng màu xanh lam (blue). Chính $\mathrm{CaCO}_{3}$ góp phần làm màu xanh của hồ đậm hơn. (Hình $4 \mathrm{a}$, Hình $5 \mathrm{a}$ ). Sự thay đổi nồng độ của $\mathrm{CaCO}_{3}$ trong nước đã làm thay đổi màu nước theo mùa [22].

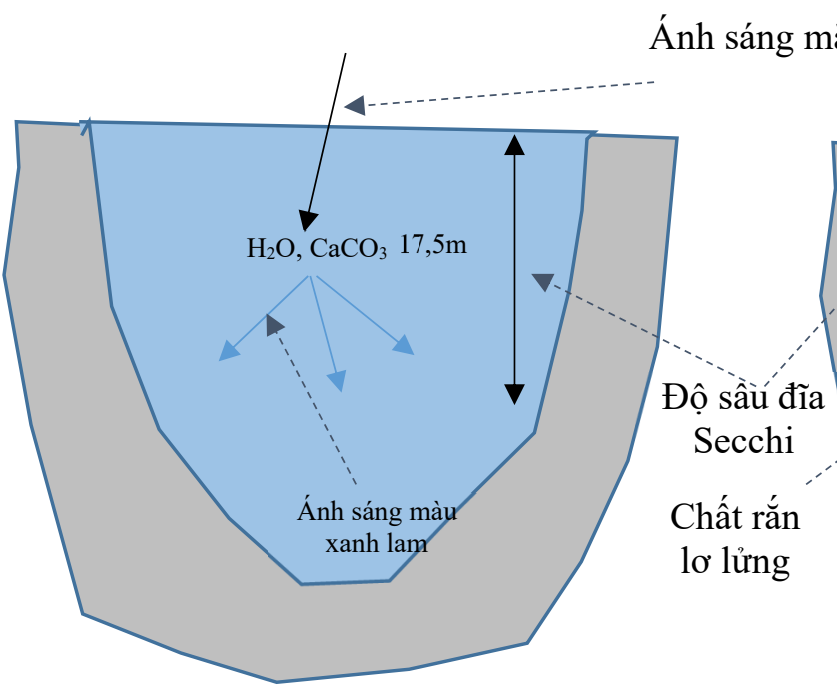

(a)

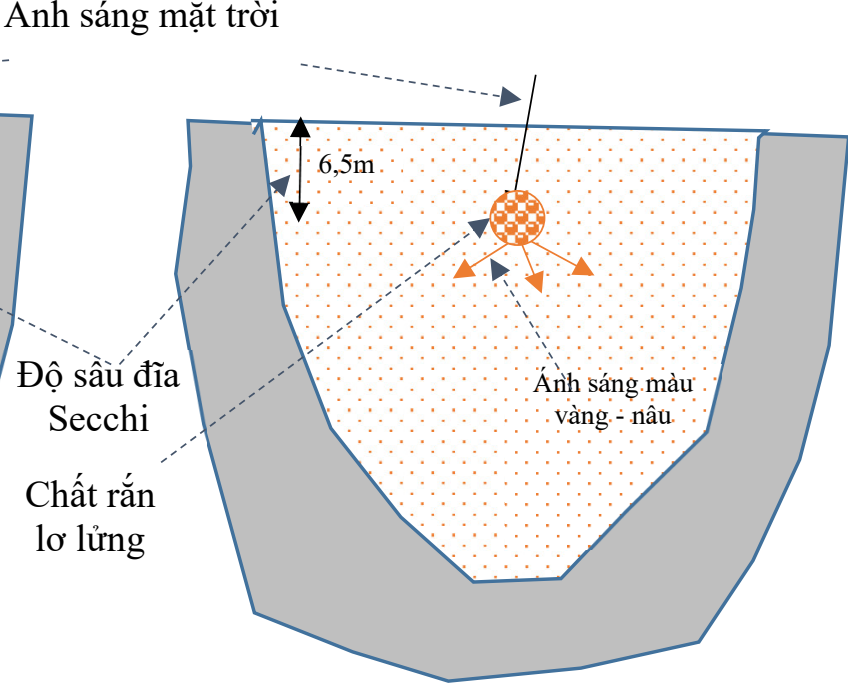

(b)

Hình 4. Tán xạ ánh sáng mặt trời trong nước hồ mùa khô (a) và mùa mưa (b).

\subsubsection{Hiện tượng nước xanh nhạt vào mùa mưa}

Vào mùa mưa nước mưa chảy tràn từ khu vực xung quanh hồ đã làm cho chất rắn lơ lửng trong hồ tăng. Kết quả phân tích cho thấy nồng độ TSS tăng từ $<0,05 \mathrm{mg} / 1$ lên đến 7,83 $\mathrm{mg} / \mathrm{l}$, độ đục tăng từ 1 NTU mùa khô lên đến 2,2 NTU mùa mưa. Độ sâu đĩa Secchi giảm từ $17,5 \mathrm{~m}$ xuống còn $6,5 \mathrm{~m}$. Khi độ đục tăng làm cho khả năng tán xạ ánh sáng màu xanh lam giảm xuống đồng thời việc tăng tán xạ ánh sáng khoảng màu vàng đến nâu (Hình $4 \mathrm{~b}$, Hình $5 b)$. Sự xuất hiện của các hợp chất humic trong chất rắn lơ lửng cũng làm thay đổi sự tán xạ 
ánh sáng trong nước hồ góp phần làm màu nước thay đổi [23]. Ngoài ra, nồng độ $\mathrm{CaCO}_{3}$ vào mùa mưa cũng giảm xuống còn $240 \mathrm{mg} / \mathrm{l}$ (Hình 2) từ đó giảm khả năng tán xạ ánh sáng xanh lam của $\mathrm{CaCO}_{3}$. Kết quả phân tích chất lượng nước cho thấy màu nước hồ có màu xanh lam nhạt hơn vào mùa mưa so với mùa khô hoàn toàn phù hợp.
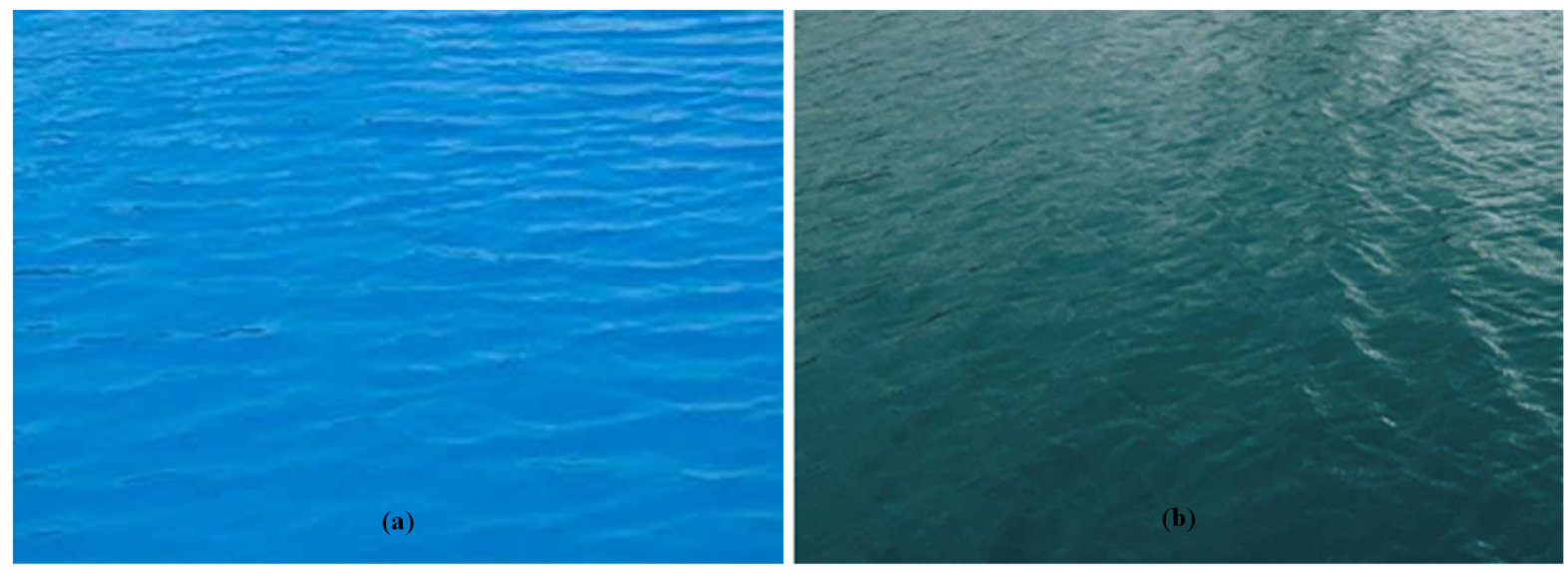

Hình 5. Màu nước hồ mùa khô (a) và mùa mưa (b).

\section{Kết luận}

Qua nghiên cứu này có thể đưa ra một số kết luận sau:

Chất lượng nước hồ ở cả hai mùa mùa mưa và mùa khô đều rất kém, chỉ số $\mathrm{WQI}=1$ thể hiện chất lượng nước tương ứng màu đỏ ô nhiễm nặng do nồng độ $\mathrm{pH}$ rất cao $(>10)$ cho cả 2 mùa.

Nguyên nhân màu nước mùa khô và mùa mưa có sự khác nhau được xác định do chất rắn lơ lửng và độ đục tăng vào mùa mưa, trong khi nồng độ $\mathrm{CaCO}_{3}$ và $\mathrm{Ca}\left(\mathrm{HCO}_{3}\right)_{2}$ giảm dẫn tới nước hồ mùa mưa tán xạ ánh sáng màu xanh lam kém, đồng thời tăng tán xạ ánh sáng khoảng màu vàng đến nâu nên nước có màu xanh lam nhạt hơn mùa khô có màu xanh lam đậm.

Nồng độ $\mathrm{pH}$ của hồ rất cao do đó để cải tạo hồ phục vụ các mục đích sử dụng nước cần làm giảm $\mathrm{pH}$ của nước hồ.

Nghiên cứu này chưa tính tới các tác động của chế độ thủy văn dòng chảy mặt và dòng chảy ngầm ảnh hưởng tới chất lượng nước hồ theo mùa. Đây cũng là một hướng nghiên cứu cần mở rộng thêm để quản lý chất lượng nước hồ tốt hơn.

Đóng góp của tác giả: Xây dựng ý tưởng nghiên cứu: Đ.H.T.; Lựa chọn phương pháp nghiên cứu: Đ.H.T.; Thu thập, phân tích, tính toán xử lý số liệu: Đ.H.T.; Viết bản thảo bài báo: Đ.H.T.; Chỉnh sửa bài báo: Đ.H.T.

Lời cam đoan: Tác giả cam đoan bài báo này là công trình nghiên cứu tác giả, chưa được công bố ở đâu, không sao chép từ những nghiên cứu trước đây; không có sự tranh chấp lợi ích.

\section{Tài liệu tham khảo}

1. Zhao, M.M.; Chen, Y.P.; Xue, L.Q.; Fan, T.T.; Emaneghemi, B. Greater health risk in wet season than in dry season in the Yellow River of the Lanzhou region. Sci. Total Environ. 2018, 644, 873-883.

2. Jiang, T.; Wang, D.Y.; Wei, S.Q.; Yan, J.L.; Liang, J.; Chen, X.S.; Liu, J.; Wang, Q.L.; Lu, S.; Gao, J.; Li, L.L.; Guo, N.; Zhao, Z. Influences of the alternation of wetdry periods on the variability of chromophoric dissolved organic matter in the water level fluctuation zone of the Three Gorges Reservoir area, China. Sci. Total Environ. 2018, 636, 249-259. 
3. Wu, T.; Wang, S.; Su, B.; Wu, H.; Wang, G. Understanding the water quality change of the Yilong Lake based on comprehensive assessment methods. Ecol. Indic. 2021, 126, 107714.

4. Hany, A.; Akl, F,; Hagras, M.; Balah, A. Assessment of recent rehabilitation projects' impact on water quality improvement in Lake Burullus, Egypt. Ain Shams Eng. J. 2021. In Press, Corrected Proof. https://doi.org/10.1016/j.asej.2021.05.006.

5. Molly, J.W.; Ted, R.A.; Matthew, P.; David, W.B.; Jonathon, J.L.; John, K.; Mari N. An assessment of water quality in two Great Lakes connecting channels. J. Great Lakes Res. 2019, 45(5), 901-911.

6. Natarajan, M.; Solai, M.S.; Johnpaul, V.; Gowrishankar, K.R.; Arun, M.; Boopalakrishnan, R. Seasonal water quality assessment in Valankulam Lake, Coimbatore. Mater. Today: Proc. 2020. In Press, Corrected Proof. https://doi.org/10.1016/j.matpr.2020.10.240.

7. Vasistha, P.; Ganguly, R. Water quality assessment of natural lakes and its importance: An overview. Mater. Today: Proc. 2020, 32, 544-552.

8. Wu, Z.; Wang, X.; Chen, Y.; Cai, Y.; Deng, J. Assessing river water quality using water quality index in Lake Taihu Basin, China. Sci. Total Environ. 2018, 612, 914922.

9. Wu, Z.; Lai, X.; Li, K. Water quality assessment of rivers in Lake Chaohu Basin (China) using water quality index. Ecol. Indic. 2021, 121, 107021.

10. Li, T.; Li, S.; Liang, C.; Bush, R.T.; Xiong, L.; Jiang, Y. A comparative assessment of Australia's Lower Lakes water quality under extreme drought and post-drought conditions using multivariate statistical techniques. J. Cleaner Prod. 2018, 190, 111 .

11. Zhao, Y.; Xia, X.H.; Yang, Z.F.; Wang, F. Assessment of water quality in Baiyangdian Lake using multivariate statistical techniques. Procedia Environ. Sci. 2012, 13, 1213-1226.

12. Kazi, T.G.; Arain, M.B.; Jamali, M.K.; Jalbani, N.; Afridi, H.I.; Sarfraz, R.A.; Baig, J.A.; Shah, Q.A. Assessment of water quality of polluted lake using multivariate statistical techniques: A case study. Ecotoxicol. Environ. Saf. 2009, 72, 301-309.

13. Lê, H.B.T.; Chế, Đ.L.; Nguyễn, H.T. So sánh kết quả đánh giá chất lượng nước bằng đánh giá toàn diện mờ và chỉ số chất lượng nước: trường hợp nghiên cứu sông Đồng Nai. Tạp chí Phát triển Khoa học và Công nghệ 2014, 17.

14. Nguyễn, V.H.; Phạm, N.A.T.; Nguyễn, M.H.; Thuỷ, C.T. Đánh giá chất lượng nước sông Bồ ở tỉnh Thừa Thiên Huế dựa vào chỉ số chất lượng nước (WQI). Tạp chí Khoa hoc, Đại học Huế 2010, 58, 77-85.

15. Lan, T.T.; Long, N.P. Assessment of surface water quality by water quality index (WQI) at the Cai Sao canal, An Giang province, Vietnam. Livest. Res. Rural Dev. 2011, 23, 151.

16. Bộ Tài nguyên và Môi trường, Quyết định số 879/QĐ-TCMT ngày 01 tháng 07 năm 2011, Tổng cục Môi trường, Hà Nội, 2011.

17. Dubey, M.; Ujjania, N.C.; Borana, K. Water Quality Index (WQI) of Sarangpani Lake, Bhopal (India). Environ. Ecol. 2016, 34-4D, 2475.

18. Suna, W.; Xiaa, C.; Xua, M.; Guoa, J.; Suna, G. Application of modified water quality indices as indicators to assess the spatial and temporal trends of water quality in the Dongjiang River. Ecol. Indic. 2016, 66, 306.

19. Lumb, A.; Sharma, T.C.; Bibeault, F.; Klawunn, P. A Comparative Study of USA and Canadian Water Quality Index Models. Water Quality. Exposure Health 2011, 3-3, 203. 
20. Đỗ, H.T.; Vũ, T.M.; Đinh. M.C. Đánh giá chất lượng nước hồ nước xanh tại xã An Sơn, huyện Thủy Nguyên, Thành phố Hải Phòng bằng chỉ số chất lượng nước (WQI), chỉ số phú dưỡng (TSI) và chỉ số ô nhiễm kim loại nặng (HPI). Tạp chí Khoa học ĐHQGHN: Các Khoa học Trái đất và Môi trừ̀ng 2017, 33, 45-54.

21. Robin, M.P.; Edward, S.F. Absorption spectrum $(380-700 \mathrm{~nm})$ of pure water. II. Integrating cavity measurements. Appl. Optics 1997, 36, 8710-8723.

22. Turoczy, N.J. Calcium chemistry of Blue Lake, Mt Gambier, Australia, and relevance to remarkable seasonal colour changes. Arch. Hydrobiol. Suppl. 2002, 156, $1-9$.

23. Andrew, L.T. Identification of processes regulating the colour and colour change in an oligotrophic, hardwater, groundwater-fed lake, Blue Lake, Mount Gambier, South Australia. Lakes Reservoirs Res. Manage. 2000, 5, 161-176.

\title{
Evaluation of seasonal water quality and determination of causes of water color change in a blue lake at An Son Commune, Thuy Nguyen District, Hai Phong City
}

\author{
Do Huu Tuan ${ }^{1}$ \\ ${ }^{1}$ Faculty of Environmental Sciences, VNU University of Science, 334 Nguyen Trai, \\ Thanh Xuan, Hanoi, Vietnam; tuandh@vnu.edu.vn
}

\begin{abstract}
Color of a lake at An Son Commune, Thuy Nguyen District, Hai Phong City changes between dry and rainy seasons. Evaluation of the lake water quality by season and the reasons of water color change between two seasons is very urgent. By sampling and analyzing chemical parameters in water and assessing water quality, the results showed that the water quality index (WQI $=1$ ) was bad Total suspended solids (TSS) increased from $0.05 \mathrm{mg} / \mathrm{l}$ in the dry season to $7.83 \mathrm{mg} / \mathrm{L}$ in rainy season and turbidity increased from 1.0 NTU in the dry season to $2.2 \mathrm{NTU}$ in the rainy season. While the concentration of $\mathrm{CaCO}_{3}$ and $\mathrm{Ca}\left(\mathrm{HCO}_{3}\right)_{2}$ both decreased in the rainy season $\left(\mathrm{CaCO}_{3}\right.$ from $304 \mathrm{mg} / \mathrm{l}$ in the dry season to $240 \mathrm{mg} / \mathrm{l}$ in the rainy season, $\mathrm{Ca}\left(\mathrm{HCO}_{3}\right)_{2}$ from $67.75 \mathrm{mg} / 1$ to $\left.47.21 \mathrm{mg} / \mathrm{l}\right)$. Sechi depth decreased from $17.5 \mathrm{~m}$ (dry season) to $6.5 \mathrm{~m}$ (rainy season). TSS and turbidity increasing, $\mathrm{CaCO}_{3}$ and $\mathrm{Ca}\left(\mathrm{HCO}_{3}\right)_{2}$ decreasing caused blue color in the rainy season less blue than the dry season.
\end{abstract}

Keywords: Lake water quality; Blue lake; Seasonal water quality change. 